\title{
Studying physics during the COVID-19 pandemic: Student assessments of learning achievement, perceived effectiveness of online recitations, and online laboratories
}

\author{
P. Klein $\odot,{ }^{1, *}$ L. Ivanjek, ${ }^{2}$ M. N. Dahlkemper $\odot,{ }^{1}$ K. Jeličić $\odot,{ }^{3}$ M.-A. Geyer®, ${ }^{2}$ \\ S. Küchemann, ${ }^{4}$ and A. Susac ${ }^{5}$ \\ ${ }^{1}$ Faculty of Physics, Physics Education Research, University of Göttingen, \\ Friedrich-Hund-Platz, 37077 Göttingen, Germany \\ ${ }^{2}$ Faculty of Physics, Physics Education Research, Technische Universität Dresden, \\ Haeckelstraße 3, 01069 Dresden, Germany \\ ${ }^{3}$ Department of Physics, Faculty of Science, University of Zagreb, Bijenička cesta 32, \\ 10000 Zagreb, Croatia \\ ${ }^{4}$ Department of Physics, Physics Education Research Group, Technische Universität Kaiserslautern, \\ Erwin-Schrödinger-Str. 46, 67663 Kaiserslautern, Germany \\ ${ }^{5}$ Faculty of Electrical Engineering and Computing, University of Zagreb, Unska 3, 10000 Zagreb, Croatia
}

(Received 13 October 2020; accepted 28 January 2021; published 11 March 2021)

The COVID-19 pandemic has significantly affected the education system worldwide, which was forced to respond with a sudden shift to distance learning. While successful distance teaching requires careful thinking, planning, and the development of technological and human resources, there was no time for preparation in the current situation. Various physics courses, including lectures, tutorials, and laboratory courses, had to be transferred to online formats, resulting in a variety of simultaneous, asynchronous, and mixed activities. To investigate how physics students perceived the sudden shift to online learning, we developed a questionnaire and gathered data from $N=578$ physics students from five universities in Germany, Austria, and Croatia. In this article, we report how the problem-solving sessions (recitations) and laboratories were adapted, how students judge the different formats of the courses, and how useful and effective they perceived them. The results are correlated with the students' self-efficacy ratings and other behavioral measures (such as self-regulated learning skills). This study is descriptive in nature, and a survey study design was implemented to examine the relationships among the variables. We found that good communication abilities $(r=0.48, p<0.001)$ and self-organization skills $(r=0.63, p<0.001)$ are positively correlated with perceived learning achievement. Furthermore, the previous duration of studies had a significant impact on several self-reported achievement measures, resulting in consistently lower scores of students in their first academic year compared with students who were further along academically. We draw conclusions and suggest implications for future online classes on the instructor and faculty level. Suggestions include (i) focusing on first-year courses with on-campus teaching when facing limited lecture hall capacities, (ii) offering special courses for promoting self-regulated learning skills, (iii) emphasizing the positive aspects of distance learning, and (iv) installing networking services for supporting student communication.

DOI: 10.1103/PhysRevPhysEducRes.17.010117

\section{INTRODUCTION}

The COVID-19 pandemic has significantly affected the education system worldwide; in response, the education system has responded with a sudden shift to distance learning.

\footnotetext{
*pascal.klein@uni-goettingen.de
}

Published by the American Physical Society under the terms of the Creative Commons Attribution 4.0 International license. Further distribution of this work must maintain attribution to the author(s) and the published article's title, journal citation, and DOI.
Although some forms of online teaching and learning existed in the system, the whole education community was suddenly forced into an unplanned and unwanted remote teaching scenario in the spring of 2020. Distance teaching requires the careful thinking, planning, and development of technological and human resources for successfully achieving the desired learning outcomes. However, in the current situation, there was very little time for preparation; the instructors had to act quickly and adapt to remote teaching. In the process, they had support from their organizations (schools and universities) in providing $e$-learning platforms and other digital learning management systems and communication tools. 
Nevertheless, the main burden was on the instructors to adjust their teaching methods and materials to an online format. The question of whether their teaching approach is still efficient when taken from the physical classroom and transferred to technological devices arises from this situation. The aim of this study was to evaluate teaching and learning processes during the COVID-19 pandemic in the context of physics courses at the university level. This article focuses on physics problem-solving sessions (so-called recitations), physics laboratory courses, and the influencing factors that were considered important for online teaching and learning during the pandemic.

\section{A. Recitations and homework problems}

A major part of university physics studies in Germany and most European countries consists of problem-solving sessions, the so-called recitations. They provide an opportunity for students to work together in a small group on challenging problems designed to build a conceptual understanding and problem-solving skills. Students apply critical thinking skills and problem-solving methods rather than repeating the material covered in the textbooks or lectures. Two forms of recitations can be distinguished: (i) live sessions, where students work together on the problems under the supervision of an instructor or lecturer, or (ii) working on the problems in their spare time on a weekly basis (typically also in groups), submitting the solutions and receiving grades and feedback. In both cases, guided discussions take place after the students have worked on the material.

Probably the most widespread forms of online tools in on-campus physics courses before the COVID-19 pandemic were web-based homework systems, such as LONCAPA, Mastering Physics, Expert TA, WebAssign, and so forth. which are usually incorporated in typical introductory physics courses, especially in the United States (they are not so common in Europe). They usually contain a large number of textbook problems with hints for students and provide automatic grading. In early studies, the online homework systems were evaluated and compared with ungraded homework and the standard methods of collecting and grading homework [1,2]. Most studies have shown that online homework systems are beneficial [3-6]; however, in general more iterations and developments of the homework system are needed to achieve the required efficiency [7]. The online homework systems described above cover only one part of physics courses and could not be used as a complete replacement for face-to-face teaching or recitations during the COVID-19 pandemic.

\section{B. Physics laboratories}

Physics laboratories are an important part of many physics courses or are implemented as independent courses. Over the last decade, we have been witnessing a growing use of novel physics lab learning environments that are designed by using platforms such as Arduino [8-10] and Raspberry Pi [11]. With the proliferation of smartphones, the use of mobile sensors in performing physics school experiments has also increased [12-14]. Remote laboratories allow for conducting real (laboratory) experiments remotely [15], whereas virtual laboratories are based on computer simulations, such as PhET [16], which enable the essential functions of laboratory experiments. The comparisons of physical and virtual laboratories in physics education has shown the advantages for each type of laboratory, so some researchers have suggested combining the two types to enhance the learning process [17-20]. A recent review found overall positive effects of remote labs on cognitive, behavioral, and affective learning outcomes, even though the authors concluded that the evaluation approaches of the learning outcomes in the reviewed studies were quite superficial [21].

Since the current situation with online courses was not anticipated, new virtual and remote labs could not be established. During the pandemic the online labs can be described as a continued instruction of courses that were originally considered as lab courses prior to the transition to online teaching. In many cases, students were supported with (artificial or real) data sheets and a video of the experiment. Within the current study, we paid particular attention to the evaluation of physics laboratories conducted online or on campus during the COVID-19 semester and, focusing on the types of data that students engaged with.

\section{Influencing factors of online teaching and learning}

While the research results from above can provide guidance for instructors on how to produce effective online teaching materials, the question of how to engage students in the learning process remains. Recent studies have reported the challenges of engaging all students in selfpaced interactive electronic learning tutorials $[22,23]$. The authors concluded that "many students in need of out-ofclass remediation via self-paced learning tools may have difficulty motivating themselves and may lack the selfregulation and time management skills to engage effectively with tools specially designed to help them learn at their own pace" [22], and they showed that the students who worked in a supervised manner performed significantly better than those working on their own [23]. The self-regulatory, motivational, and social characteristics of students play an important role in their engagement with peers in online forums [24] and online physics courses in general [25]. This might be an important issue for learning processes during the pandemic, so we decided to evaluate several behavioral measures of student learning.

First, students' self-organization abilities in general and during the COVID-19 semester were taken into account. We measured the degree to which students are metacognitively, motivationally, and behaviorally active participants in their own learning process, that is, to which extent students can take a proactive role in monitoring their learning, 
maintaining motivation, and engaging in behaviors (e.g., study strategies) that lead to academic success.

Second, we also aimed at evaluating students' соттиnication (with their peers and instructors). It can be assumed that the easiest part in the rapid transition to remote learning was to have students work individually. Since learning at universities is done within a social context, it becomes important to understand how communication between the lecturer and students and among students is perceived in an (almost exclusive) online learning environment.

Third, the technical conditions, for example, the accessibility to a computer and stable internet connection, and their environment were considered, for example, whether students had access to a quiet place to study for attending video conferences.

Fourth, students' attitudes toward online learning were in the scope of our research to identify their general attitude toward online learning.

Finally, we asked for students' perceived learning achievements and expected learning outcomes. Students' beliefs about their capabilities or likelihood of success reveal important information about different course structures, how these might vary between different groups of students, and how these are presumably correlated to the factors listed above.

\section{Research questions}

The aim of the study is to provide insights into the effects of the pandemic on the teaching and learning processes within university physics courses, hence helping instructors improve their online courses during the current COVID-19 pandemic and for future online courses in general. This study is descriptive in nature, and a survey study design was implemented to examine the relationships among the variables.

In this paper, the following four research questions are addressed:

RQ1 What is the relationship between perceived learning effectiveness during the COVID-19 summer term and the various behavioral aspects that are important in digital teaching?

RQ2 What are the differences between students of different study progress levels concerning the behavioral aspects and learning effectiveness?

RQ3 What formats were used to establish online problem-solving sessions, and how have they been rated by the students in terms of effectiveness?

RQ4 What formats were used to establish online physics laboratories, and how have they been rated by the students in terms of effectiveness?

While the first and second research questions address all the physics students who participated in the study, the third and fourth questions are specific to the students who participated in the corresponding courses, that is, problem-solving sessions and physics laboratories, respectively. The effectiveness was assessed in terms of student self-reports and not by performance on tests or examinations due to the design of the study as a large-scale anonymous mid-end-term evaluation.

\section{METHODS}

\section{A. Questionnaire development}

Based on the common literature for evaluating online teaching and learning, we identified several aspects that were considered relevant for physics student learning in the current situation of the compulsory and involuntary change to online teaching. The aspects included an evaluation of simultaneous and asynchronous activities, students' attitudes toward online learning, communication abilities, technical and social aspects, and self-organization abilities.

While inspecting the literature, the scale for selforganization abilities was detected and implemented [26]; however, the other scales from existing research required an adaptation due to the sudden switch to distance learning caused by the COVID-19 pandemic. For assessing the selfefficacy, the self-efficacy scale from the Motivated Strategies for Learning Questionnaire (MSLQ) has been adapted to our situation $[27,28]$, while the aspect of self-organization during the specific COVID-19 situation was developed by the authors. In addition, 18 semistructured interviews were conducted in order to get deeper insights in the current situation. The interviews were used to formulate the missing items of different aspects that were not found in previous literature. We used an iterative process based on the close exchange between all the researchers involved in the current study.

Furthermore, course structures that were typical for physics studies were also in the scope of interest, i.e., the recitations, the physics laboratories and the physics labs for prospective teachers. The final questionnaire included 246 technical data fields; the questionnaire is available in English, German, and Croatian. The English version of the questionnaire is presented in the Supplemental Material [29]. Because a rigorous analysis and validation process of the instrument is not in the scope of this paper, we restrict the presentation of the instrument characteristics to the measures presented in Sec. II B. In the work presented here, we focus on the students' attitudes toward online learning, communication abilities, technical and social aspects, and self-organization abilities, as well as the recitations and physics laboratories. For the latter two, the organization of the courses has also been assessed. Evaluation of the physics lectures and seminars in simultaneous and asynchronous formats are part of another work [30].

\section{B. Instrument characteristics}

Table I provides the characteristics of the scales. All items were assessed using a 4-point Likert-type scale; thus the means range between 1 and 4 points, where high values correspond to high abilities. Additionally, the Supplemental Material [29] reports about the psychometric validation of 
TABLE I. Description and psychometric characteristics of the scales that were used for all students.

\begin{tabular}{|c|c|c|c|c|}
\hline Scale & No. items & Sample item & $\alpha$ & Mean \pm standard deviation $(\%)$ \\
\hline $\begin{array}{l}\text { Self-organization abilities } \\
\text { in general }\end{array}$ & 5 & $\begin{array}{l}\text { In my studies, I am self-disciplined } \\
\text { and I find it easy to set aside } \\
\text { reading and homework time. }\end{array}$ & 0.76 & $2.97 \pm 0.57(65.6 \pm 25.5) \%$ \\
\hline $\begin{array}{l}\text { Self-organization abilities } \\
\text { during the COVID-19 } \\
\text { semester }\end{array}$ & 6 & $\begin{array}{l}\text { Not being at university hinders } \\
\text { me from studying }\end{array}$ & 0.78 & $2.41 \pm 0.67(47.1 \pm 22.4) \%$ \\
\hline Environment & 2 & $\begin{array}{l}\text { I have a quiet space where I can participate } \\
\text { in video conferences unhindered. }\end{array}$ & 0.74 & $3.11 \pm 0.76(70.4 \pm 19.1) \%$ \\
\hline $\begin{array}{l}\text { Attitudes toward online } \\
\text { learning }\end{array}$ & 6 & $\begin{array}{l}\text { On-campus instruction helps me understand } \\
\text { the physics concepts better than } \\
\text { in online courses. }\end{array}$ & 0.90 & $2.16 \pm 0.80(38.7 \pm 26.5) \%$ \\
\hline Communication & 4 & $\begin{array}{l}\text { It is easy for me to establish contact with other } \\
\text { students during the COVID-19 pandemic. }\end{array}$ & 0.72 & $2.36 \pm 0.70(45.32 \pm 23.3) \%$ \\
\hline Learning achievement & 7 & $\begin{array}{l}\text { I am certain that I will complete the online } \\
\text { physics courses with good grades. }\end{array}$ & 0.88 & $2.56 \pm 0.66(51.9 \pm 22.6) \%$ \\
\hline
\end{tabular}

*Negative statements were reversed for the analysis.

the instrument structure using a confirmatory factor analysis [29]. All scales were positively checked to be one dimensional. Normality was checked using histogram plots (also reported in the Supplemental Material [29]).

The internal consistency of a component is measured by the reliability coefficient Cronbach's $\alpha$. The measure indicates how well the items "fit together," meaning that it examines whether or not a test is constructed of parallel items that address the same construct. Cronbach's $\alpha$ ranges from 0 to 1 , and values above 0.7 are considered reliable for group measurements.

The face validity of the statements were checked by expert reviews of item formulation using an iterative process and close exchange between all co-authors. Since the questionnaire was administered only once, reconsidering item formulations and adding or removing items based on an iterative process will follow.

\section{Data collection and sample}

The questionnaire was imported into Questback and distributed to physics students via mailing lists in mid-June and late July. Therefore, this is a mid-end-term evaluation for all participating universities. If certain course formats were not taken (e.g., the physics labs or the recitations), no questions were asked. The distribution of the questionnaire was done either centrally by the faculties' deans of studies or by faculty members.

Overall, the participation link was sent to 2700 students, and 873 students clicked on the link (32.3\%). We received completed questionnaires from 578 physics students (352 male, 226 female), yielding participation rates of $21.4 \%$ (total participation rate, TPR) and 66.2\% (adjusted participation rate, APR), as measured by the invited students or completed surveys and interested students or completed survey, respectively. TPR ranged from 11\% (Dresden) to $57 \%$ (Zagreb), and APR ranged from 53\% (Kaiserslautern) to $72 \%$ (Göttingen). The average time for answering the questionnaire was $24 \mathrm{~min} 37 \mathrm{sec}$. Table II shows the distribution of the locations. Most students who participated in the study were in low semesters $(63.5 \%$ of the sample studied for less than 2.5 years), and only a few students exceeded the standard duration of physics study (3.3\%). The students attended 5.2 courses on average, 3.4 of which were physics courses (66\%). The nonphysics courses consisted of mathematical courses, educational courses, soft skills, and others. More than one-third of the students reported that they spend more than $40 \mathrm{~h}$ studying per week, and about one out of five students reported investing less than $20 \mathrm{~h}$ a week

TABLE II. Information about the sample.

\begin{tabular}{|c|c|c|c|c|c|c|c|}
\hline \multicolumn{8}{|c|}{ Duration of studying physics (Years of physics studied) } \\
\hline University $^{\mathrm{a}}$ & Total sample & Male $(\%)$ & $<1 \mathrm{yr}$ & $1-2.5 \mathrm{yr}$ & $3-4.5 \mathrm{yr}$ & $5-6 \mathrm{yr}$ & $>6 \mathrm{yr}$ \\
\hline Dresden & 114 & $73(64.0)$ & $39(34.2)$ & $30(26.3)$ & $30(26.3)$ & $12(10.5)$ & $1(0.9)$ \\
\hline Göttingen & 232 & $144(62.1)$ & $83(35.8)$ & $62(26.7)$ & $62(26.7)$ & $19(8.2)$ & $6(2.6)$ \\
\hline Kaiserslautern & 9 & $5(55.6)$ & $4(44.4)$ & $2(22.2)$ & $\ldots$ & $2(22.2)$ & $1(11.1)$ \\
\hline Wien & 138 & $85(61.6)$ & $30(21.7)$ & $65(47.1)$ & $24(17.4)$ & $11(8.0)$ & $7(5.1)$ \\
\hline Zagreb & 85 & $45(52.9)$ & $25(29.4)$ & $27(31.8)$ & $23(27.1)$ & $6(7.1)$ & $4(4.7)$ \\
\hline Total & 578 & $352(60.9)$ & $181(31.3)$ & $186(32.2)$ & $139(24.2)$ & $50(8.7)$ & $19(3.3)$ \\
\hline
\end{tabular}

${ }^{\mathrm{a}}$ A description of the participating universities can be found in the Supplemental Material [29]. 


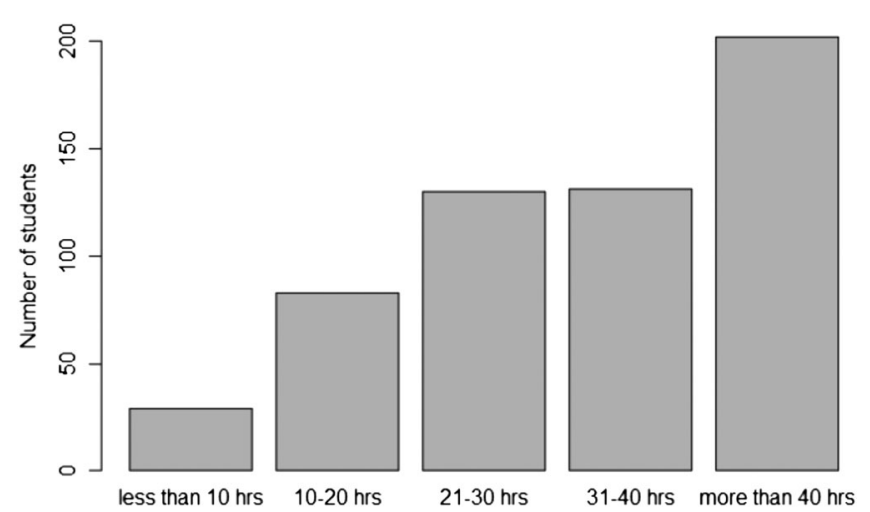

FIG. 1. Time per week spent studying.

studying (Fig. 1). Half of the students claim that they invested more time studying during the COVID-19 summer term than in the previous semester.

Concerning the technical resources, almost all students reported having permanent access to a PC (95\%) and to a fast and stable internet connection ( $81 \%$ agreement). However, only about half of the students had access to a printer (54\%).

\section{Data analysis}

For determining the relationships between the different variables (RQ1), Pearson's correlation coefficient is used. This measures the linear correlation between two variables $X$ and $Y$ and ranges from -1 to 1 . A value of +1 means total positive linear correlation, 0 is no linear correlation, and -1 is total negative linear correlation. To analyze the differences among group means in a sample (RQ2), an analysis of variance (ANOVA) is used. An ANOVA provides a statistical test of whether two or more means of a dependent variable (as defined by the components) are equal among different groups, hence generalizing the $t$ test beyond two means. When several dependent variables are considered that are intercorrelated (RQ1), a multivariate analysis of variance (MANOVA) should be used. It examines the differences on several dependent variables simultaneously to account for the intercorrelation. If the ANOVA or MANOVA yields a significant result, post hoc analyses determine which levels of the dependent variable differ from the others regarding the dependent variable. For answering RQ3 and RQ4, ANOVAs are conducted to measure the impact of different course formats on students' perceived course effectiveness.

\section{RESULTS}

\section{A. Correlation analysis and group comparisons (RQ1 and RQ2)}

Table III presents the correlation coefficients for each pair of variables. To account for multiple testing, a Bonferroni correction was used to determine the level of significance $(p=0.05 / 15=0.003)$. We observe that
TABLE III. Correlation analysis. Only significant correlations (Pearson's $r ; p<0.003$ ) are presented.

\begin{tabular}{lccccc}
\hline \hline & \multicolumn{5}{c}{ Scales } \\
\cline { 2 - 7 } & 1 & 2 & 3 & 4 & 5 \\
\hline (6) Learning achievement & 0.33 & 0.63 & 0.32 & 0.58 & 0.48 \\
(1) Self-organization general & 1 & 0.37 & 0.17 & n.s. & 0.20 \\
(2) Self-organization COVID-19 & $\ldots$ & 1 & 0.33 & 0.62 & 0.48 \\
(3) Environment & $\ldots$ & $\ldots$ & 1 & 0.19 & 0.28 \\
(4) Attitudes toward onl. learn. & $\ldots$ & $\ldots$ & $\ldots$ & 1 & 0.41 \\
(5) Communication & $\ldots$ & $\ldots$ & $\ldots$ & $\ldots$ & 1 \\
\hline \hline
\end{tabular}

students' perceived learning success is positively correlated with high abilities of self-organization in general, with selforganization in this specific situation, with access to a study-friendly environment and the ability to communicate with peers and lecturers. It is also positively correlated with students' attitudes toward online learning. In other words, students who have a positive attitude toward online learning also expect a higher learning achievement. The strongest relationships are displayed in Fig. 2.

To investigate how different groups of students responded to the different types of questions, a MANOVA with the duration of studies (DOS) (cf. Table II) as the independent (group) variable is performed. The results show that DOS had a significant multivariate influence across all variables, Wilks $\lambda=0.87, F(30,2250)=2.76, p<10^{-6}$. Given the significant multivariate effect, ANOVAs are then performed for each dependent variable using Bonferroni correction to determine significance levels. The duration of studies had a significant impact on perceived learning achievement $\left[F(5,567)=13.1, p<10^{-4}\right]$, which is shown in Fig. 2 (right), but on no other variable. Pairwise comparisons revealed that students who study physics for less than a year obtain significantly lower scores than all other groups of students ( $p=0.01$ to $p=0.001)$. There is no statistical significant difference between any other student groups regarding this variable.

\section{B. Recitations (RQ3)}

\section{General information and recitation organization}

There are 401 datasets from students who attended recitations, 287 of which were related to introductory physics courses with large audiences (>30 students), 91 of which were related to special courses with few students (e.g., special lectures in physics master studies), and 42 others (mathematical physics or special courses for prospective physics teachers). Note that some students took part in more than one course. In almost all cases (97\%), exercise sheets were provided. The exercise sheets were mostly discussed in weekly online meetings with a lecturer (89\%). The exercise sheets were compulsory in $76 \%$ of the cases. The students reported high engagement when solving the problem sheets; here, $82 \%$ of the students 

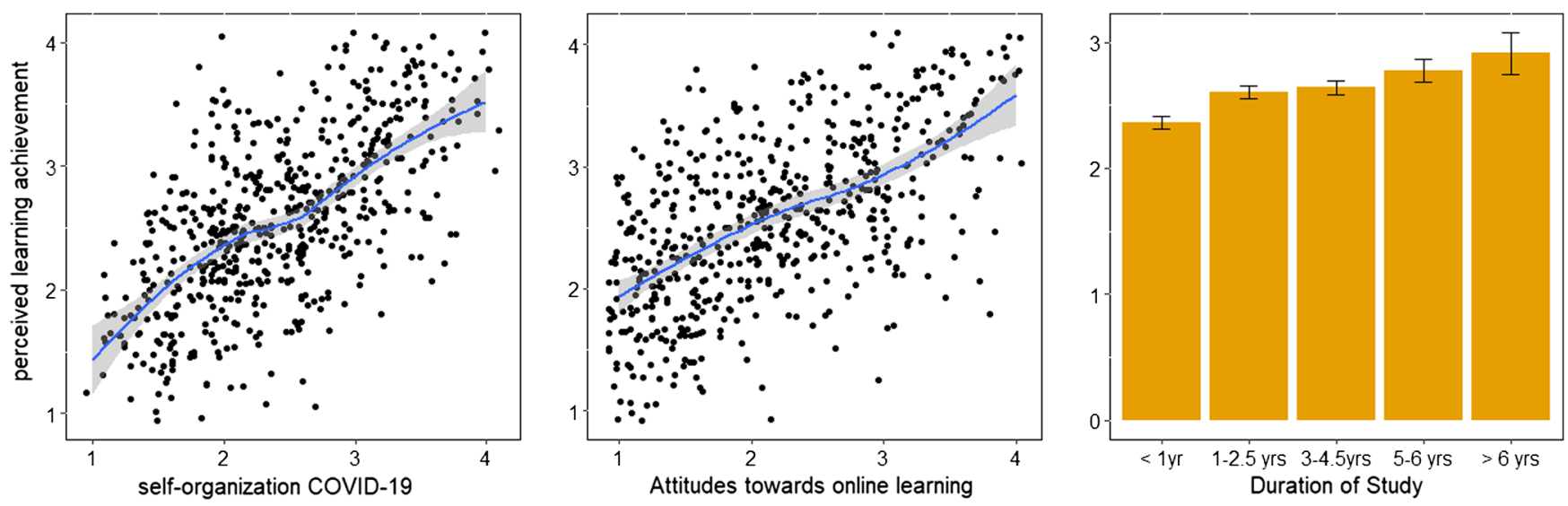

FIG. 2. Scatter plots of learning achievement versus self-organization abilities during the COVID-19 pandemic (left) and student attitudes toward online learning (center), including a smoothed fit curve with confidence region. A small jitter was added to the data points to avoid overlapping. High values represent high success or abilities. Right: Learning achievement (perceived by the students) versus duration of study. The error bar represents the standard error of the mean.

attempted to solve more than $60 \%$ of the tasks, and $58 \%$ dealt with more than $80 \%$ of the tasks. The students worked on the tasks in groups in $50 \%$ of the cases; due to the pandemic lockdown, they did not meet in person (only $4 \%$ did) but instead organized their meetings mostly via web conference or used messengers for communication.

\section{Recitation formats: What was used and what would be optimal?}

Based on the student interviews, different online formats of the recitations were identified that could be assessed in terms of the following aspects (true or false):

- (submission) The students' solutions were submitted, corrected by the tutor, and discussed in an online meeting

- (reconstruction) The solutions were reconstructed during a live online session in real time

- (live) Exercise sheets were solved live online and discussed in groups

- (handouts) The solutions to the exercise sheets were handed out to the students as text or as a video (worked-out solutions)

- (forum) Forums were used to discuss exercise sheets without time constraints.

The students marked what formats they had actually experienced (more than one option could be chosen) and what format they considered optimal for future online recitations (single choice). Figure 3 shows the fraction of total answers for each category. Because of the different assessment types (multiple choice versus single choice), statistical comparisons are inappropriate. However, comparing the relative counts within each data series, the students were less interested in handouts of solutions but wanted to work together live on exercise sheets. In line with that result, we observe that forums are perceived to be ineffective for the recitations.

\section{Perceived effectiveness of recitations}

For evaluating the perceived effectiveness of the online recitations, we assessed the student's agreement concerning seven questions on a 4-point Likert-type scale, for example, whether they felt well supervised concerning their questions during $e$-learning or whether the recitations were helpful to foster their understanding. The scores are normally distributed (mean $=2.20$, corresponding to $40.2 \%$ ), and the reliability of this scale is $\alpha=0.82$. It is worth noting that the perceived effectiveness of the recitations is highly correlated with the perceived overall learning achievement $(r=0.66, p<0.01)$.

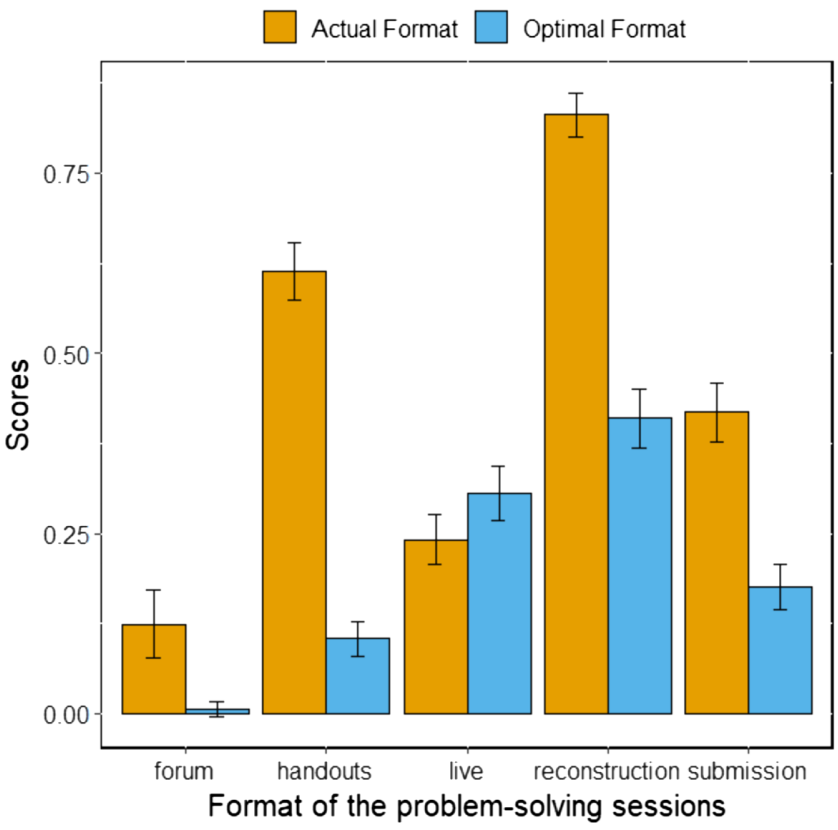

FIG. 3. Formats of the online recitations that students actually experienced during the COVID-19 summer term and judgments about optimal recitation. 
To investigate whether different groups of students or different course formats had an impact on the students' perceived effectiveness of the online recitations, ANOVAs were performed. First, a significant between-subjects effect was found for the duration of studies $[F(4,389)=5.04, p=$ 0.001], and the Bonferroni-corrected post hoc comparisons revealed that students who spent more than $6 \mathrm{yr}$ studying physics perceived the recitations as more effective than every other group of students (mean score: 2.95 , corresponding to $65 \% ; p<0.01)$. Second, groups of students were defined based on their experienced format of the recitations (see Sec. III B 2). It was observed that students who sent their own solution to be rated $(N=168)$ assessed the effectiveness of the recitations significantly higher than students who did not $(N=227), F(1,393)=6.74, p=0.01$.

\section{The physics laboratories (RQ4)}

\section{General information and lab organization}

In total, 220 physics students were enrolled in physics laboratories that were adapted to an online lab in most cases $(82 \%)$. In a few cases (10\%), students could visit the laboratories of the university, or a mixture of live and online labs were used (8\%). For the online laboratories, the experimental work was enabled either (a) using simulations and evaluating simulated data or gathering data from the simulation, (b) using videos of real experiments and extracting data from the video, or (c) working with data gathered by someone else. There were some single statements (less than 5\%) about other formats, for example, replacing the labs by student talks or using smartphones for data collection at home, that were not further considered. Hence, three different student groups according to the data source can be defined (simulated data, real data gathered by the students themselves, and real data gathered by someone else).

\section{Effectiveness of the physics laboratories}

To evaluate the perceived effectiveness of the physics laboratories, eight questions were included in the questionnaire. One set of questions deals with the experimental skills that were acquired during the lab course (5 questions, $\alpha=0.75$, sample item "I gained less experimental skills due to the modified course format"), and another set of questions asked about reinforcing content (3 questions, $\alpha=0.63$, sample item "The modified physics lab helped me to better understand the physics concepts behind the experiments").

To find out whether different groups of students perceived the two aspects of the physics laboratories differently, ANOVAs were conducted. First, the duration of the study had a significant impact on students' perceived acquisition of experimental skills, $F(3,204)=4.41, p<$ 0.01 . The students in their first academic year perceived the labs as less effective concerning experimental skills

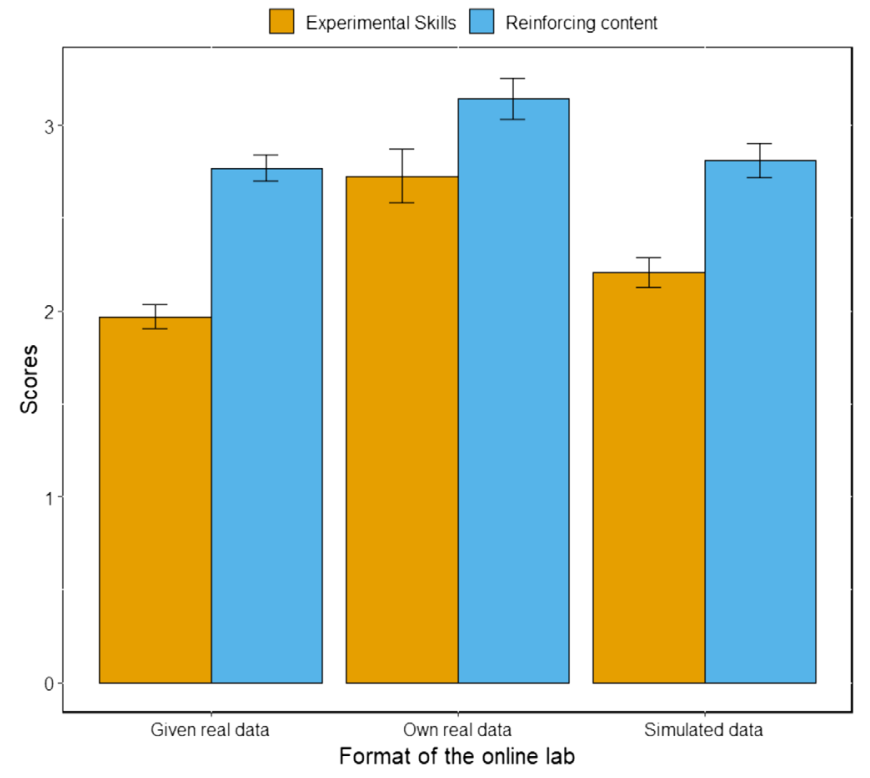

FIG. 4. Evaluation of the physics lab with respect to different types of data.

compared with students in their second year. There was no such difference concerning the reinforcement of content. Second, the type of data that were analyzed by the students had a significant impact on both scales, the acquisition of experimental skills $[F(2,198)=14.2, p<0.001)]$, and the reinforcement of content $[F(2,216)=3.50, p=0.03]$. The Bonferroni-corrected post hoc comparisons revealed that students assessed significant higher scores when they gathered the data by themselves (e.g., from a video) compared with simulated data or data that were handed out; see Fig. 4.

\section{DISCUSSION}

\section{A. Factors that are correlated with subjective learning achievement during the COVID-19 pandemic}

From the measurement perspective, all questionnaires that have been used show a good reliability, and the students' scores were reasonably normally distributed. The perceived learning achievement was positively correlated with students' self-organization abilities $(r=0.33)$, particularly in the COVID-19 pandemic $(r=0.63)$. While researchers have pointed out the benefits of metacognitive strategies such as the self-regulation of learning on problem-solving skills before [31,32], the correlation between self-organization skills during the COVID-19 pandemic and learning achievement $(r=0.63)$ was surprisingly strong. Even though no causal relationship was proven, we encourage physics faculties to offer special courses for promoting self-regulated learning skills, for example, including time management training, encouraging note taking, setting pace, and so forth. The need for this is demonstrated by the rather low mean value of the scale 
(47.1\%, cf. Table I). During the interviews that have been conducted beforehand, many students found it difficult to structure their daily routines and keep up with their usual learning pace. Supporting students with strategies for how to improve their self-organization might presumably also improve students' learning achievement.

Moreover, we also found a high correlation between communication and learning achievement. One explanation might be that high-performing students are better socialized and, hence, find communication opportunities more easily than lower-performing students. Or vice versa, good communication is a prerequisite for successful study, especially in physics, where complex phenomena and problems are studied and solved in pairs and groups. Interactions with lecturers and peers can help create an atmosphere of commitment to understanding [33]. When engagement with lecturers and other interested learners is hindered due to the distance, weaker students are potentially left behind. A constructivistic perspective advocates for active learning formats where students are engaged in writing, talking, describing, explaining, and reflectingthese processes that require careful thinking and planning when switching from the lecture hall to online lectures. To promote communication between the lecturer and students, the instructor not only presents material but also asks questions, uses interactive quizzes, and stops periodically to encourage group discussions; just what makes a good face-to-face lecture as well [34-36]. To establish communication between the students, networking services can be installed, where peers can meet and form learning groups. During the online classes, break-out rooms can create an atmosphere in which a small group of students can exchange ideas without the permanent (online) presence of an instructor. Keeping the groups small can foster collaborations.

For the attitudes toward online learning, we found a positive correlation to the perceived learning achievement. A positive attitude toward distance learning was found to be positively correlated to subjective and objective academic learning achievement in other work [37], and we also found that this attitude is correlated with self-organization skills and communication. Besides improving communication and self-organization skills as suggested above, we further recommend that instructors make the students aware of the positive aspects of distance learning, that is, permanent access to video-taped lectures, easier implementation of simulations and videos, saving traveling time, and so forth.

\section{B. First-year students rate learning achievement the lowest}

The analysis of different student groups based on their duration of studies revealed that the first-year students reported significantly lower subjective learning achievement than all the other groups of students. Possible explanations for this may be that (i) the first-year students have had the least contact with other students at university so far, meaning that their communication suffers, (ii) the self-organization skills of experienced students are more pronounced, (iii) the first-year students have had less contact with online teaching so far, their attitudes are also worse, or (iv) that they are more cautious in their performance assessment, regardless of the online teaching situation, because they have had less experience of success than older students (who are still studying). There was no difference concerning communication, self-organization skills, and students' attitudes toward online teaching between the different age groups; hence, (i)-(iii) cannot be supported by the data. However, our dataset contained no students who started their study in spring 2020, so all students in the lowest duration group were in their second academic semester. Extrapolating the trend given in Fig. 2(c), we can assume an even larger gap for the freshmen who start in the next terms. When faculties start to offer on-campus teaching again with limited capacities, we suggest focusing on freshmen students.

In line with this result, we found that students who spent six years or more studying physics rate the effectiveness of the recitations higher than the younger students and that the first-year students rated the perceived acquisition of experimental skills the lowest. Note that the sample size is different for each comparison (since not every student took part in recitations or laboratories).

\section{Recitations and tutors' feedback on solutions are important for subjective learning achievement}

For the recitations, a high correlation between the perceived effectiveness of the recitations and subjective learning achievement was found. The exercise sheets (tasks) to be worked on in self-study helped form a link between the reception of the course contents during lecture and active work on the associated problems. Given the high degree of self-activity of the students, the recitations are often regarded as the decisive basis for actual learning, contributing significantly to the knowledge construction of the students and are essential for the understanding of physics $[38,39]$. The students were asked how the recitations were designed during the COVID-19 pandemic and what format they would prefer. A major discrepancy between the actual and optimal format is present for the handout of solutions. The students preferred live discussions and reconstructions of problem solutions over the distribution of solutions. Furthermore, the students who received graded feedback on their own solutions perceived the recitations as more effective than the students who received no feedback. Both results are plausible from an educational perspective; first, group discussions, corporate problem-solving activities, and active exchange are crucial parts of face-to-face recitations and cannot be replaced by the handout of solutions that requires retracing the solution on their own. Second, it is known that receiving cognitive 
feedback can be associated with increased performance [40], and weaker students especially benefit from feedback comments-regardless of the actual quality of the feedback [41]. Feedback on one's solutions help make errors visible, can evoke new ideas on how to approach problems, and help identify weaknesses that otherwise remain undetected.

\section{The physics laboratories were considered the most successful when the students' own data were collected}

Here, 220 students took part in an online physics lab course that was mandatory for the participants. We did not evaluate the intended learning goals of the physics laboratories but decided to ask about the reinforcement of the content and building of experimental skills. These two goals are present in the research literature around lab courses, and most often, the courses focus on skills or on both aspects [42]. The items asked, for example, about conceptual mastery of the subject matter (reinforcing content) or assessment of students' ability to make measurements and collect accurate data (experimental skills).

The students most often reported performing measurements through videos of experiments (both videos recorded by the instructor or publicly available), to use simulations to generate data, or just to analyze the given datasets with no engagement with the experimental equipment. Some students reported watching an instructor doing the experiment, having a description and a picture of the experiment, or controlling physical equipment remotely. Based on the variety of the responses, we identified three categories to characterize the data students analyzed: (i) students were supported with real data taken from someone else, (ii) students used simulated data taken by themselves, and (iii) students gathered data by themselves from a real experiment (that was videotaped, remotely controlled, or actually performed). Earlier studies suggested that it is possible to use secondhand data for the purpose of evaluation and interpretation without significant distortions of epistemic learning processes [43].

In contrast, our results show that the students perceived higher learning success when they gathered data on their own, here for both, reinforcing the physics content and acquisition of experimental skills. While Priemer, Pfeiler, and Ludwig [43] noted that students got enough information on how the data were generated, we did not ask for this information. For cases in which the use of secondhand data is preferred, we encourage the lecturers to provide this information. Furthermore, in the study by Priemer, Pfeiler, and Ludwig [43] student engagement with the experiment was controlled among the students (working with firsthand or secondhand data). In our case, working with secondhand data might have been connected with lower engagement because a data evaluation does not necessarily require dealing with the apparatus. In contrast, gathering one's own data does.

\section{E. Limitations}

The current study has some limitations. From a methodological perspective, we relied purely on self-assessments and subjective estimations of learning and attitudes. Even though the results are consistent with educational notions, selfreports by students must be viewed with some caution. Particularly regarding self-reported learning gains, there have been a number of studies which reported that there is only a weak or no correlation between the self-reported and actual learning gain [44-46]. In a recent study, Deslauriers et al. [47] also found that the self-reported "feeling of learning" in a passive learning setting was higher than in an active setting, whereas the actual learning outcome was the opposite [47]. Future work could also investigate exam results or other hard indicators of learning (such as concept tests) for a more objective data basis. Furthermore, the sample represents a selection of universities that were accessible to the

TABLE IV. Observations from the study and suggestions for practical implications. For more details, please refer to the textual discussion. Achievement and success refer to students' self-reports.

\begin{tabular}{|c|c|}
\hline Observation and result & Implication \\
\hline $\begin{array}{l}\text { Self-organization abilities correlate with achievement; } \\
\text { low values during the COVID-19 pandemic }\end{array}$ & Offer special courses for promoting self-regulated learning skills \\
\hline Communication correlates with achievement & $\begin{array}{l}\text { Instructor level: asks questions (more than usual), } \\
\text { use interactive quizzes, stop periodically to encourage } \\
\text { group discussions, use break-out rooms; Faculty level: } \\
\text { install networking services, keep groups small }\end{array}$ \\
\hline $\begin{array}{l}\text { Attitudes toward online learning correlates } \\
\text { with achievement }\end{array}$ & Emphasize the positive aspects of distance learning \\
\hline Young students suffer most from distance learning & $\begin{array}{l}\text { On-campus teaching with limited capacities should focus } \\
\text { on first-year courses }\end{array}$ \\
\hline $\begin{array}{l}\text { Recitations: Receiving graded feedback has } \\
\text { positive impact on learning }\end{array}$ & $\begin{array}{l}\text { Give graded feedback, offer live discussions and reconstructions } \\
\text { of problem solutions. Avoid solely handing out solutions. }\end{array}$ \\
\hline $\begin{array}{l}\text { Labs: Gathering own data is related } \\
\text { to higher success }\end{array}$ & $\begin{array}{l}\text { Let students gather data on their own using video-experiments, } \\
\text { remote experiments, or smartphone experiments. In cases in } \\
\text { which the use of secondhand data is preferred, we encourage lecturers } \\
\text { to provide this information. }\end{array}$ \\
\hline
\end{tabular}


researchers. A wider distribution of the questionnaire involving more countries and different institutions would increase the generalizability of the results. The total participation rates are consistent with response rates garnered in other survey studies among students [48-50]. The low participation rate might be due to several reasons, for example feeling "bombarded" with questionnaires during the online semester, demands on students' time, or perceiving no personal relevance of the survey [49]. Finally, the questionnaire was administered only once as a mid-to-end-term evaluation during the spring of 2020. When students get more accustomed to online learning or hybrid models of learning, some variables (self-organization or communication) might improve.

\section{CONCLUSION}

In this descriptive study in the spring of 2020, more than 500 students from five European universities were assessed; the goal was to obtain information of how studying physics during the COVID-19 pandemic was experienced. For this purpose, a multidimensional questionnaire was developed that turned out to have satisfactory psychometric properties; nevertheless, revisions during future iterations will follow.
Here, we reported the results about online problem-solving sessions, the online physics laboratories, and the factors influencing subjective learning outcomes. Even though being descriptive in nature (and therefore lacking controlled experimental manipulations), we derived several suggestions from the study for future physics courses in which online learning will certainly play an important role. We summarize our main findings in Table IV.

The results presented here may be helpful for other faculties when it comes to planning online teaching and learning in general and during the next terms. The close cooperation with colleagues from the physics departments has proven to be very successful, especially in the implementation of the questions and distribution and reporting of the results during faculty meetings. From a metaperspective, the current article also shows how education research can bridge the (sometimes existent) gap between physics education and the faculty of physics. It would be desirable if similar work has more space in the future and also at other institutions.

\section{ACKNOWLEDGMENTS}

We acknowledge support by the Open Access Publication Funds of the Göttingen University.
[1] S. Bonham, R. Beichner, and D. Deardorff, Online homework: Does it make a difference?, Phys. Teach. 39, 293 (2001).

[2] K. K. Cheng, B. A. Thacker, R. L. Cardenas, and C. Crouch, Using an online homework system enhances students' learning of physics concepts in an introductory physics course, Am. J. Phys. 72, 1447 (2004).

[3] M. Thoennessen and M. J. Harrison, Computer-assisted assignments in a large physics class, Comput. Educ. 27, 141 (1996).

[4] N. Demirci, of web-based vs. paper-based homework in a general physics, Eurasia J. Math. Sci. Technol. Educ. 3, 29 (2007).

[5] G. Kortemeyer, E. Kashy, W. Benenson, and W. Bauer, Experiences using the open-source learning content management and assessment system LON-CAPA in introductory physics courses, Am. J. Phys. 76, 438 (2008).

[6] W. R. Evans and M. A. Selen, Investigating the use of mastery-style online homework exercises in introductory algebra-based mechanics in a controlled clinical study, Phys. Rev. Phys. Educ. Res. 13, 020119 (2017).

[7] B. Gutmann, G. Gladding, M. Lundsgaard, and T. Stelzer, Mastery-style homework exercises in introductory physics courses: Implementation matters, Phys. Rev. Phys. Educ. Res. 14, 010128 (2018).

[8] Š. Kubínová and J. Šlégr, Physics demonstrations with the Arduino board, Phys. Educ. 50, 472 (2015).

[9] W. H. Kuan, C. H. Tseng, S. Chen, and C. C. Wong, Development of a computer-assisted instrumentation curriculum for physics students: Using LabVIEW and Arduino platform, J. Sci. Educ. Technol. 25, 427 (2016).

[10] P. La Rocca, F. Riggi, and C. Pinto, Remotely teaching Arduino by means of an online simulator, Phys. Edu. 55, 063003 (2020).

[11] A. Mandanici and G. Mandaglio, Experiments and data analysis on one-dimensional motion with Raspberry Pi and Python, Phys. Educ. 55, 033006 (2020).

[12] P. Vogt and J. Kuhn, Analyzing free fall with a smartphone acceleration sensor, Phys. Teach. 50, 182 (2012).

[13] L. Sukariasih, Erniwati, L. Sahara, L. Hariroh, and S. Fayanto, Studies the use of smartphone sensor for physics learning, Int. J. Sci. Technol. Res. 8, 862 (2019), http:// www.ijstr.org/final-print/oct2019/Studies-The-Use-OfSmartphone-Sensor-For-Physics-Learning.pdf.

[14] S. Staacks, S.Hütz, H. Heinke, and C. Stampfer, Advanced tools for smartphone-based experiments: phyphox, Phys. Educ. 53, 045009 (2018).

[15] S. Gröber, M. Vetter, B. Eckert, and H. J. Jodl, Experimenting from a distance-Remotely controlled laboratory (RCL), Eur. J. Phys. 28, 127 (2007).

[16] N. D. Finkelstein, W. K. Adams, C. J. Keller, P. B. Kohl, K. K. Perkins, N. S. Podolefsky, S. Reid, and R. Lemaster, When learning about the real world is better done virtually: A study of substituting computer simulations for laboratory equipment, Phys. Rev. ST Phys. Educ. Res. 1, 1 (2005). 
[17] Z. C. de Jong, Ton Linn, and Marcia C. Zacharia, Physical and virtual laboratories in science and engineering education, Science 340, 305 (2013).

[18] J. R. Brinson, Learning outcome achievement in nontraditional (virtual and remote) versus traditional (handson) laboratories: A review of the empirical research, Comput. Educ. 87, 218 (2015).

[19] S. J. Husnaini and S. Chen, Effects of guided inquiry virtual and physical laboratories on conceptual understanding, inquiry performance, scientific inquiry self-efficacy, and enjoyment, Phys. Rev. Phys. Educ. Res. 15, 010119 (2019).

[20] A. Reagan, Online introductory physics labs: Status and methods, Wash. Acad. Sci. 98, 31 (2012), https://www .washacadsci.org/Journal/Journalarticles/V.98-1-online_ physics_labs_aReagan.pdf.

[21] L. S. Post, P. Guo, N. Saab, and W. Admiraal, Effects of remote labs on cognitive, behavioral, and affective learning outcomes in higher education, Comput. Educ. 140, 103596 (2019).

[22] S. Devore, E. Marshman, and C. Singh, Challenge of engaging all students via self-paced interactive electronic learning tutorials for introductory physics, Phys. Rev. Phys. Educ. Res. 13, 010127 (2017).

[23] E. Marshman, S. DeVore, and C. Singh, Holistic framework to help students learn effectively from researchvalidated self-paced learning tools, Phys. Rev. Phys. Educ. Res. 16, 020108 (2020).

[24] A. Traxler, A. Gavrin, and R. Lindell, Networks identify productive forum discussions, Phys. Rev. Phys. Educ. Res. 14, 020107 (2018).

[25] J. W. T. Pond and J. J. Chini, Exploring student learning profiles in algebra-based studio physics: A person-centered approach, Phys. Rev. Phys. Educ. Res. 13, 010119 (2017).

[26] R. M. Bernard, A. Brauer, P. C. Abrami, and M. Surkes, The development of a questionnaire for predicting online learning achievement, Distance Educ. 25, 31 (2004).

[27] P. R. Pintrich, D. A. F. Smith, T. Garcia, and W. J. McKeachie, A Manual for the Use of the Motivated Strategies for Learning Questionnaire (MSLQ) (National Center for Research to Improve Postsecondary Teaching and Learning, University of Michigan, Ann Arbor, MI, 1991).

[28] P. R. Pintrich, D. A. F. Smith, T. Garcia, and W. J. McKeachie, Reliability and predictive validity of the Motivated Strategies for Learning Questionnaire (MSLQ), Educ. Psychol. Meas. 53, 801 (1993).

[29] See Supplemental Material at http://link.aps.org/ supplemental/10.1103/PhysRevPhysEducRes.17.010117 for (i) demographic information about the participating universities, (ii) a full list of test items, and (iii) the psychometric validation of the scales using confirmatory factor analysis.

[30] L. Ivanjek, P. Klein, M.-A. Geyer, K. Jeličić, S. Küchemann, M. N. Dahlkemper, and A. Susac (to be published).

[31] D. Rickey and A. M. Stacy, The role of metacognition in learning chemistry, J. Chem. Educ. 77, 915 (2000).

[32] G. Schraw, K. Crippen, and K. Hartley, Promoting selfregulation in science education: Metacognition as part of a broader perspective on learning, Res. Sci. Educ. 36, 111 (2006).
[33] R. J. Dufresne, W. J. Gerace, W. J. Leonard, J. P. Mestre, and L. Wenk, Classtalk: A classroom communication system for active learning, J. Comp. High. Educ. 7, 3 (1996).

[34] E. Mazur, Peer Instruction: A User's Manual, Unpublished Manuscript, Department of Physics (Harvard University, Cambridge, MA, 1993).

[35] D. R. Sokoloff and R. K. Thornton, Using interactive lecture demonstrations to create an active learning environment, Phys. Teach. 35, 340 (1997).

[36] A. Van Heuvelen, Overview, case study physics, Am. J. Phys. 59, 898 (1991).

[37] A. M. Uzun, E. Unal, and A. Yamac, Service teachers' academic achievements in online distance education: The roles of online self-regulation and attitudes, Turk. Online J. Dist. Educ. 14, 131 (2013), https://eric.ed.gov/? id=EJ1013774.

[38] N. D. Finkelstein and S. J. Pollock, Replicating and understanding successful innovations: Implementing tutorials in introductory physics, Phys. Rev. ST Phys. Educ. Res. 1, 010101 (2005).

[39] B. T. Spike and N. D. Finkelstein, Preparing tutorial and recitation instructors: A pedagogical approach to focusing attention on content and student reasoning, Am. J. Phys. 80, 1020 (2012).

[40] N. Duncan, Feed-forward: improving students' use of tutors' comments, Assess. Eval. Higher Educ. 32, 271 (2007).

[41] S. Gielen, E. Peeters, F. Dochy, P. Onghena, and K. Struyven, Improving the effectiveness of peer feedback for learning, Learn. Instr. 20, 304 (2010).

[42] B. R. Wilcox and H. J. Lewandowski, Developing skills versus reinforcing concepts in physics labs: Insight from a survey of students' beliefs about experimental physics, Phys. Rev. Phys. Educ. Res. 13, 010108 (2017).

[43] B. Priemer, S. Pfeiler, and T. Ludwig, Firsthand or secondhand data in school labs: It does not make a difference, Phys. Rev. Phys. Educ. Res. 16, 013102 (2020).

[44] N. A. Bowman, Assessing learning and development among diverse college students, New Dir. Institutional Res. 2010, 53 (2010).

[45] N. A. Bowman, Validity of college self-reported gains at diverse institutions, Educational Res. 40, 22 (2011).

[46] S. R. Porter, Self-reported learning gains: A theory and test of college student survey response, Res. High. Educ. 54, 201 (2013).

[47] L. Deslauriers, L. S. McCarty, K. Miller, K. Callaghan, and G. Kestin, Measuring actual learning versus feeling of learning in response to being actively engaged in the classroom, Proc. Natl. Acad. Sci. U.S.A. 116, 19251 (2019).

[48] D. D. Nulty, The adequacy of response rates to online and paper surveys: what can be done?, Assessment Eval. Higher Educ. 33, 301 (2008).

[49] L. J. Sax, S. K. Gilmartin, and A. N. Bryant, Assessing response rates and nonresponse bias in web and paper surveys, Res. High. Educ. 44, 409 (2003).

[50] E. L. Dey, Working with low survey response rates: The efficacy of weighing adjustments, Res. High. Educ. 38, 215 (1997). 